\title{
BEYOND THE HEALTHCARE PARADIGM: CO- CREATING A NEW MODEL FOR COLLABORATIVE TRANSDISCIPLINARY HEALTHCARE DESIGN EDUCATION
}

\author{
Ashley HALL ${ }^{1}$, Daniel LEFF ${ }^{2}$, Anna WOJDECKA ${ }^{1}$, James KINROSS ${ }^{2}$, Paul THOMPSON ${ }^{1}$ \\ and Ara DARZI ${ }^{2}$ \\ ${ }^{1}$ Royal College of Art \\ ${ }^{2}$ Imperial College London
}

\begin{abstract}
Although healthcare has long been a focus for design research dating from the 1960's and Bruce Archer's Industrial Design (Engineering) research unit, there remain very few academic programmes in the field of healthcare design and even fewer that go beyond classic user driven models. This paper reports on a unique collaboration between the Royal College of Art and Imperial College in London to develop an innovative partnership and programme structure between two diverse collaborating institutions. Moreover, the partnership has shown how new design and healthcare research methods have been used for innovative practice-based healthcare design projects. We reflect on the diverse skill sets and approaches that have evolved through collaborative teamwork between healthcare practitioners, designers and diverse disciplinary backgrounds. Our conclusions illustrate how a context driven programme provides evidence of a new 'post-disciplinary' mindset and explores implications for research and practice for the future of healthcare design.
\end{abstract}

\section{Keywords: Healthcare design, transdisciplinary education, design innovation, future of health}

\section{INTRODUCTION}

High quality healthcare systems represent a significant and growing economic burden; In 2018, US healthcare expenditure rose to $20 \%$ of GDP at $\$ 3.6 \mathrm{tn}$ [1] equal to around $\$ 10,000$ per person per year, [2] while in the UK expenditure in 2016 was $£ 191.7 \mathrm{bn}$. $£ 152 \mathrm{bn}$ of this sum was funded by the UK government, accounting for just under 10\% of GDP [3] and a \$4,200 cost per person annually [2]. These costs are no longer sustainable, and design innovation represents an increasingly important methodology for improving the efficacy, safety and efficiency of healthcare interventions or therapies.

Healthcare and wellbeing have long been central concerns for design going back to its foundation. Bruce Archer was an earlier pioneer of health design and he made significant contributions through his design of the hospital bed. The history of his work for the NHS has been documented by Ghislane [4] at the Royal College of Art. Whilst healthcare has long been a concern for design activity and medical collaboration, few educational programmes have been developed specifically for Healthcare Design. The focus for this paper is twofold; 1) to describe the pedagogic rationale for developing a collaborative postgraduate healthcare design programme and 2) to provide insights for the development of novel healthcare innovation methods, practices and disciplinary observations.

The global context for developing a new healthcare design approach has been driven by a number of factors illustrated in Figure 1. These including increasing economic constraints [1,2,3] and a long-term increase in wicked problems such as the rise in non-communicable diseases associated with western cultures and ageing, opiate addiction etc. Considerable progress has been made in our understanding of some of the drivers for wicked problems [7,8] and emerging technologies serve as attractive potential interventions. These have in turn been driven by advances in computational biology, synthetic biology and omics sciences (e.g. CRISPR) as well as through the developments in big data sciences, deep learning and artificial intelligence. Data visualisation platforms such as VR/AR/MR also provide completely novel vehicles through which designers and healthcare providers can visualise, experience 
and collaboratively solve wicked problems. A major change has also been seen in the engagement of large corporate multinational firms that are seeking to leverage their technology in the healthcare markets (e.g. The big five tech companies, Apple, Google, Amazon, Microsoft and Facebook amongst others). The significant pace of change has in turn driven the need to train a new generation of healthcare designers who are capable of tackling complex wicked problems through the application of a broad portfolio of methods from across the healthcare and design domains for patient benefit. In synergy with the advancement of new exponential technologies and an increasing trend towards consumer health, a strong branch of healthcare design is moving from reactive healthcare towards prevention and behaviour change. Democratisation of access to new technologies allows solutions with global impact.

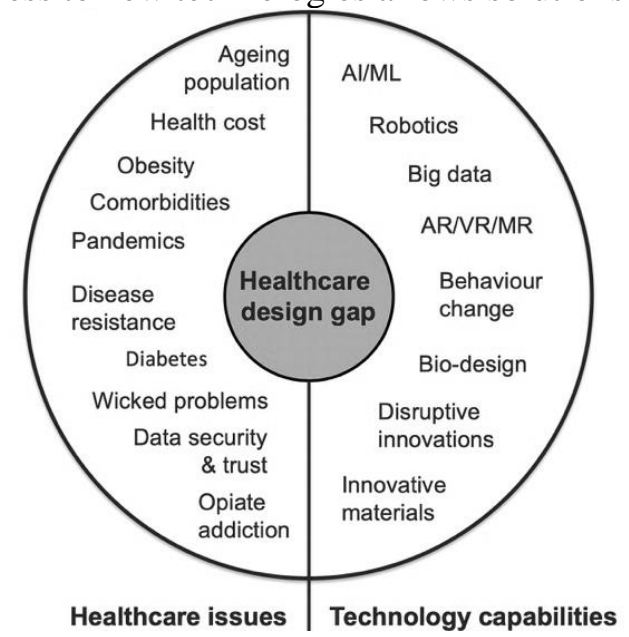

Figure 1. Healthcare design challenge space showing examples of issues and capabilities

\section{INNOVATIVE PARTNERSHIP}

The establishment of the Helix Centre [9] followed a successful HEFCE catalyst grant in 2014 involving the Royal College of Art (RCA) with the Helen Hamlyn Design Centre and the Medical School at Imperial College London. Its aim was to create the first healthcare design consultancy inside a UK NHS hospital. As part of this commitment the partners agreed to establish a shared postgraduate master's programme to focus on healthcare challenges and new solutions that could also interact with and benefit from expertise gained from the Helix Centre.

Curriculum development planned to bring together medical and healthcare expertise from the Medical School and design led innovation methods from the RCA in a balance of modules led by Imperial, the RCA and both in partnership at a balance of around a third each. The innovation approach delivered by the RCA was based on principles and pedagogic methods developed by two of the co-authors who had previously been involved as teaching staff delivering the two-year full-time MA/MSc double masters Innovation Design Engineering programme between the RCA and Imperial [10]. The programme would be delivered through eight modules delivered part-time over two years in two-week 'burst-mode' format with an additional major design-research project resulting in tested tangible healthcare innovations accompanied by a thesis (Fig.2). The RCA would offer a masters of research (MRes) and Imperial a master's of science (MSc) using the same collaboratively developed curriculum. We initially expected the RCA to recruit designers mostly from industrial and product design and Imperial to recruit healthcare professionals. However, the course attracted a much wider crossover group spanning healthcare and design practices including social science, anthropology, architecture, fine art, fashion design, occupational health, paramedics and user interaction designers. We found that a number of designers applied to the Imperial MSc and healthcare professionals to the RCA MRes creating a much more mixed learning environment than anticipated. Two examples of the transdisciplinary partnership between healthcare and design can be seen in Fig. 3 (left) where the Helix Design Dash module formed students into cross disciplinary healthcare, design and diverse disciplinary groups to tackle the redesign of the Charing Cross Hospital Breast Care Services patient experience. Initially three mixed groups investigated different focus areas around patient's emotional journeys through the unit considering the impact of test results on individuals and the cross-flow of patients and clients. The final design concepts were presented to a panel including the director of the Breast Care Unit, CEO of the NHS Trust Charity and resulted in support to implement the design innovations in the redesign and refurbishment of the 
unit based on designing empathic patient experience. The behaviour change module (Fig 3. right) combined behavioural science theory including the COM-B method [11] with innovative design interaction technologies from Bare Conductive who have developed a digital ink which can be used to sense resistance and movement.

\begin{tabular}{|c|c|c|}
\hline \multirow{3}{*}{} & \multicolumn{2}{|c|}{ MSc Healthcare and Design } \\
\hline \multirow{4}{*}{ Year 1 } & Module 1a: Introduction to principles of design and innovation & Module 1b: Introduction to health and Healthcare (7.5 ECTS) \\
\cline { 2 - 3 } & Module 2: Introduction to design led innovation in healthcare (7.5 ECTS) \\
\cline { 2 - 3 } & Module 3: Health research toolkit (7.5 ECTS) \\
\cline { 2 - 3 } & Module 4: Helix Design Dash (7.5 ECTS) \\
\hline \multirow{3}{*}{ Year 2 } & Module 5: Innovation (7.5 ECTS) \\
\cline { 2 - 3 } & Module 6: Behaviour Change (7.5 ECTS) \\
\cline { 2 - 3 } & Module 7: Design for Business toolkit (7.5 ECTS) \\
\cline { 2 - 3 } & Module 8: Leadership (7.5 ECTS) \\
\hline Year 1 \& 2 & Research Project (Joint supervised over 2 years 30 ECTS) \\
\hline
\end{tabular}

Figure 2. MRes/MSc Curriculum

The COM-B behaviour change method and Bare Conductive technology were used together to develop new healthcare innovations aimed at prompting more healthy behaviours. This was achieved with 'deep dive' immersion into the Bare Conductive technology where students often with little or no previous knowledge of coding were producing interactions at the end of the first day.

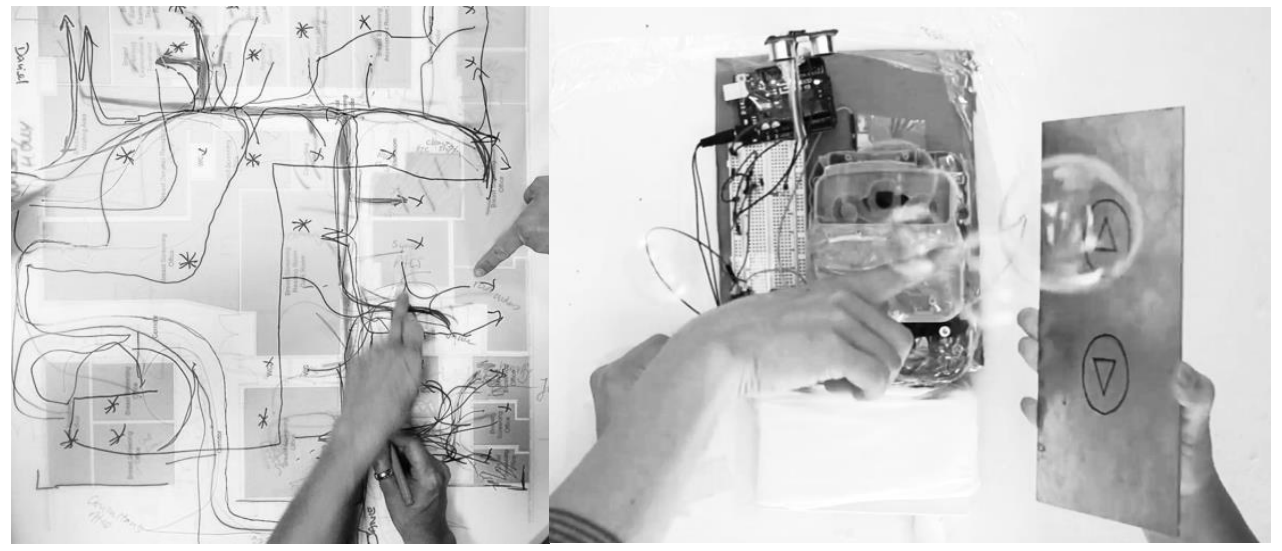

Figure 3. Helix Design Dash module redesigning Charing Cross breast care services patient experience and behaviour change module prototyping

Examples of major project focus areas included research which aimed to design out obesity through experimenting with an innovative design for clothing that increases friction and effort in small amounts during the whole day resulting in more calorie burn with the advantage of being introduced as subtle lifestyle intervention. The fashion design background of the design researcher along with the deep medical expertise brought about this new combination of methods (Fig. 4 left). Another project collaborated with the Great Ormond Street hospital and focussed on the issue of high levels of anxiety from paediatric patients with chronic conditions while awaiting surgery. The communication design background of this student was of great benefit in developing a series of books through which children could explore stories and exchange their thoughts and fears with characters in a way that would help healthcare professionals to deal more effectively with issues of preoperational stress and anxiety (Fig. 4 centre). Research has shown that pre-operational stress increases post-operational pain [12]. Improving clinical interactions for young adults with type 1 diabetes tackled the major issue of the fall-off in healthcare services engagement between child and adult care regimes for diabetes patients. The user interaction design background of the researcher enabled the development of a new engagement process that can more accurately time regime changeover and provide a more integrated support facility from family member and clinicians (Fig. 4 right). A central part of the curriculum ethos, and one that has become increasingly important as the programme has developed, has been the 'space' between two very different institutions and two disciplines delivered in largely different teaching formats. While conventional wisdom may be to synthesise the collaborative areas as much as possible, the space 
between both has become a breeding ground for students to move outside of their home discipline and to reinvent themselves in a post disciplinary healthcare space. It has also become the landscape on which healthcare needs and capabilities have met with design thinking and innovative methods applied through new technologies.

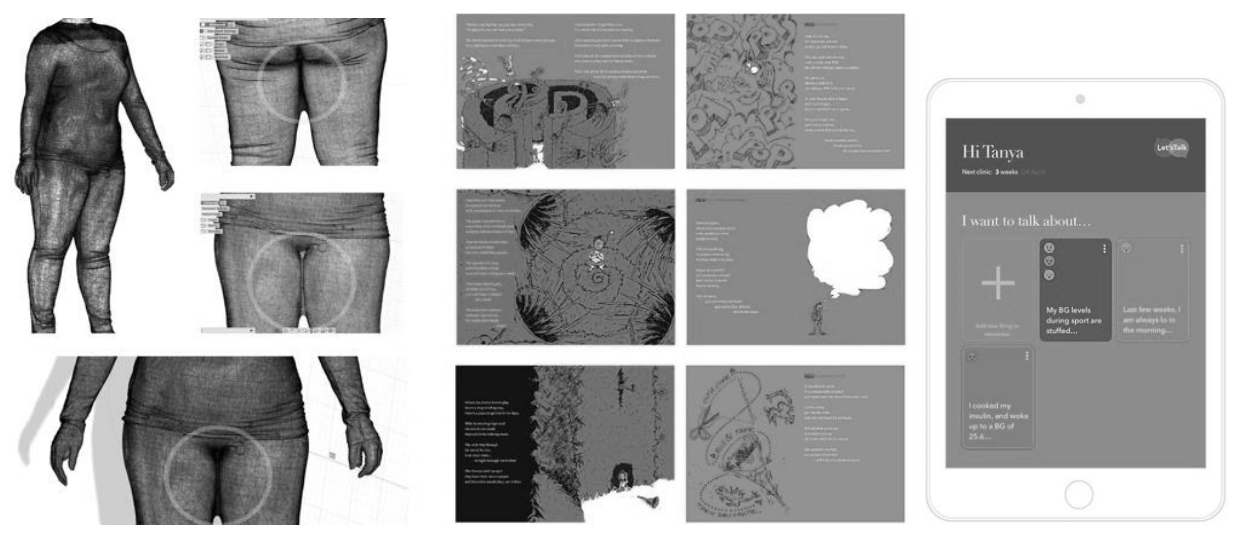

Figure 4. Major project examples: Lindsay D'Arcy Designing out Obesity, Philippa Batey Reducing Anxiety in Paediatric Patients, Tim Allen Improving Clinical Interactions for Young Adults with diabetes

Moreover, the space between institutions, disciplinary practices and languages is a fertile ground for creativity through serendipitous exchanges, communications and even miscommunications [13] upon which creative methods can feed new concepts and innovations. These disciplinary movement are akin to Rodgers and Bremner's concept of alterplinary practice [14] where conventional sets of disciplinary methods are rejected in favour of an open choice for combining diverse sets of influences (Figure 5).
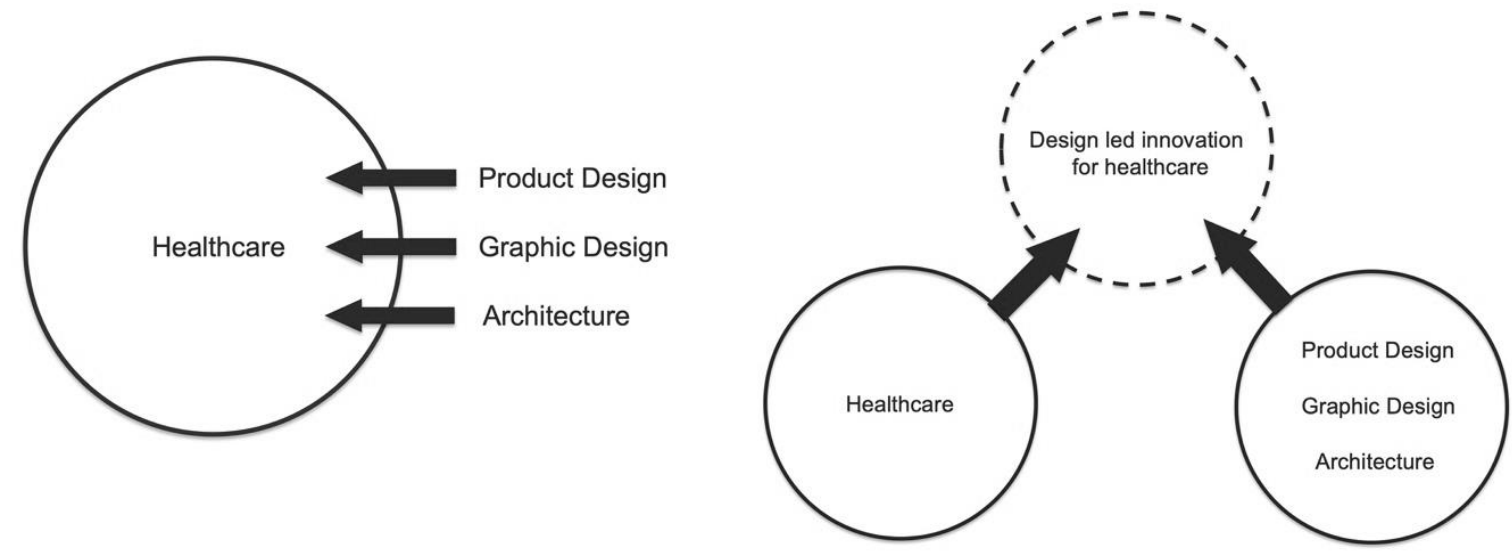

Figure 5. Focus from designing into healthcare $(L)$ to a new healthcare design pedagogic $\operatorname{space}(R)$

\section{NEW DESIGN AND MEDICAL RESEARCH METHODS}

When compared to the range of programmes on offer at the RCA, the MRes Healthcare Design is unique in offering a design context rather than a design discipline. In many ways this has been crucial in developing an opportunity for a much richer set of methods, approaches and frameworks across healthcare and design to cross fertilise transdisciplinary solutions for tackling major healthcare issues where current practices are limited by solo disciplinary perspectives. Seeing new perspectives on current and emerging healthcare challenge areas opens up the space for new methods and technologies to deliver new solutions. Therefore, we need to move beyond classic user driven design (UCD) models that tend to dominate healthcare design and find the new combinations of experimental research models that leverage post-disciplinary collaborations and incorporate future foresight, including advancement of new technologies within global contexts. Alongside the undoubted benefits of using UCD difficulties can arise with its use within complex systems, wicked problems, power relations and cultural factors [15], and it has issues reconciling design researcher expertise with levels of user driven insights and norming. Whether students are envisioning new futures for healthcare landscapes of growth, 
disciplinarity, collapse or transformation [16], novel methods are needed to see differently and to project new future routes to inform us as to the goals along the way. Envisioning different alternative futures also enables understanding of the broader context and anchoring the design research and innovation within a preferable future [17]. One example comes from a student using statistical analysis to gain empirical evidence in the first research stage then using speculative design to open up future innovation routes that go beyond linear roadmaps allowing conversations for both positive and negative outcomes. This contrasts with the technology led innovation model prevalent in healthcare when humans more often than not cope with technologies that are applied rather than have solutions designed to match varied behavioural and psychological abilities and responses.

Innovative contexts require innovative methods and one example comes from a current student whose focus is on the potentially beneficial knowledge exchange between veterinary medicine and human medicine. This illustrates how two areas that have traditionally had little interaction could benefit from new creative ideas to support innovation and knowledge exchange. In this instance healthcare design is focussed on designing improved exchanges creating new environments of trust. Extreme medicine is also a challenging context for designers in trying to empathise with treating people in microgravity environments and increased radiation in space. While replicating a space environment on earth is extremely challenging there are simulations, creative tools and processes that can support designers in familiarising themselves with this uniquely challenging healthcare context.

\section{REFLECTIONS, OBERVATIONS AND INSIGHTS}

From a design perspective one of the interesting observations has been recognising the empathy skills of medical professionals and the capability of a goal driven mindset delivering results in complex changing institutional settings. This entrepreneurial attitude combined with design and innovation skills is opening up new opportunities in the transdisciplinary healthcare design space. Using a combination of group work and design sprints has freed up thinking to move beyond discipline and lay the groundwork for training a new generation of strategic healthcare designers who are familiar with medical and healthcare environments, understand the capacity of technology to deliver profound benefits (and risks) while combining creative methods in new formats to suit changing environmental needs. Embedding a number of the modules in the Imperial College St Mary's Hospital campus in Paddington brings with it the opportunity for designers to familiarise themselves with healthcare environments and also for healthcare professions to see design thinking operating in their professional workplaces. The 'burst mode' model has brought with it access to a whole new market for the RCA where this model of delivery is very different to the full-time studio masters offering. Healthcare Design MRes and MSc students are mostly employed full time and bring the learning from modules back into their workplace directly extending the learning across the spaces between the burst modes. This model has also brought with it an executive level attitude as many of the students fly in and fly out after the two-week module block from destinations including Mexico, Brazil, US West and East coast, India, China, Canada, Netherlands, Greece and Spain. The short high intensity sessions away from day jobs brings a full focus and concentration on rapid upskilling.

The burst mode modules: introduction to principles of design led innovation, introduction to health and healthcare, design led innovation in healthcare, research toolkit, Helix Design Dash, leadership, innovation, behaviour change, business toolkit and leadership with a 2 years design research project has largely been successful. Apart from changing the order of some of the modules we have realised that the separate introductions for designers and healthcare professionals did not work as planned as not all of those from design backgrounds would have been exposed to innovation through user centred design methods for example. The same is also true of healthcare professionals who are also not necessarily aware of some of the overarching concepts in the field including NHS structure and the healthcare economy. The rapidly expanding nature of applicants from more diverse disciplines has allowed us to revisit this part of the course and redesign it as an introduction for wider entry backgrounds and support the development of a transdisciplinary healthcare masters offering. Current and future challenges involve integrating the increasing need for technology competence and design led innovation. As new complex technologies like artificial intelligence and machine learning commercially develop, some of this skill set arrives with students, while those without familiarity in this field develop deep skills in the burst mode model. However, this can only be supported if employers are willing to encourage and support this alongside the programme. Other challenges include the philosophy and practice of healthcare design ethics. Specifically, in terms of how new technologies are asking ethical questions 
around treatment and when design is the agent of these issues being raised it can challenge healthcare designers where practices, principles and debates are under-developed. In terms of practicalities these involve matching the aspirations and needs of postgraduate level research with the length and duration of institutional healthcare ethics processes. The conventional framework of ethical approval such as the Integrated Research Application System may need to be re-visited to better support the needs of healthcare design researchers, such that the highest ethical standards are maintained and yet design innovation can flourish as opposed to being stifled.

\section{POST DISCIPLINARY MINDSET (CONCLUSIONS)}

The concept of a paired set of contexts driven healthcare design master's courses has shown signs of a post disciplinary mindset emerging in a form that has allowed students to practice beyond traditional sets of disciplinary methods and approaches. Designers have benefitted from a much deeper disciplinary exposure alongside understanding the overarching principles of health and healthcare. Design in a healthcare context as opposed to healthcare design as a discipline has freed up new ways of thinking that are essential for innovative solutions in environments for healthcare design in the future. The new methods combinations could provide powerful innovative results and many of these are being tested in ongoing live projects. The range of output modes from architectural and spatial interiors projects through to products, user interactions, experience designs, service design, software, design practices, methods, prototypes, diagnosis applications and design tools covers a very wide spectrum reinforcing the discipline free space within which students are researching and designing. The implications for future healthcare design research and practice supports new ways of educating healthcare designers, innovative methods combinations, new ways of embedding design into health and heath into design alongside technology skilling and adoption. Fundamentally the development, acceptance and success of a post disciplinary mindset in healthcare design will depend as much on the leadership, ambition and skill of this new breed of hybrid specialist as much as on the trust and investment from healthcare environments.

\section{REFERENCES}

[1] Altarum, (2018), Insight report, Retrieved 10th February 2019, https://altarum.org/sites/ default/files/uploaded-related-files/SHSS-Spending-Brief_August_2018.pdf

[2] OECD, (2018), Spending on Health Latest Trends, Retrieved 10th February 2019, http://www.oecd.org/health/health-systems/Health-Spending-Latest-Trends-Brief.pdf

[3] Office for National Statistics, (2018), Retrieved 10th February 2019, https://www.ons.gov.uk/peoplepopulationandcommunity/healthandsocialcare/

[4] Ghislaine L. (2001) Hospital beds by design: a socio-historical account of the 'King's Fund Bed', 1960-1975. PhD thesis, British Library Ethos service.

[5] Boyd Davis S. and Gristwood S. (2016) The Structure of Design Processes: Ideal and Reality in Bruce Archer's 1968 Doctoral Thesis, DRS, Brighton.

[6] Archer B. (1978) Time for a Revolution in Art \& Design Education. RCA Papers, (6).

[7] Rittel H. and Webber M. (1973) Dilemmas in a general theory of planning, Policy Sci, 4.

[8] Buchanan R. (1992). Wicked problems in design thinking. Design Issues, 8(2), 5-21.

[9] Helix Centre, Retrieved 10th February 2019, https://helixcentre.com

[10] Hall A. and Childs P. (2009). Innovation design engineering: Non-linear progressive education for diverse intakes. E\&PDE, University of Brighton, UK, pp. 312-317

[11] Michie S., Stralen M. and West R. (2011), The behaviour change wheel: A new method for characterising and designing behaviour change interventions, Imp. Sci. 2011; 6: 42.

[12] Kain Z., et al, (2006). Preoperative Anxiety, Postoperative Pain, and Behavioural Recovery in Young Children Undergoing Surgery. Paediatrics, 118(2), pp. 651-658.

[13] Torrisi S. and Hall A. (2013), Missing Miscommunications in Interdisciplinary Design Practice, $E P D E$, Dublin Institute of Technology, Ireland.

[14] Rodgers P. and Bremner C. (2011) Alterplinarity - 'Alternative Disciplinarity' in Future Art and Design Research Pursuits. Studies in Material Thinking, 6. pp. 1-16. ISSN 1177-6234

[15] Gulliksen J., Lantz A. and Boivie I. (1999). User Centred Design - Problems and Possibilities: A summary of the 1998 PDC \& CSCW workshop, SIGCHI Bulletin, Vol. 31, No. 2, 25 April 1999.

[16] Dator J. (2002). Advancing Futures: Futures Studies in Higher Education. Westport, Connecticut: Praeger, ISBN-13: 978-0275976323

[17] Voros J. (2003). 'A generic foresight process framework', Foresight, vol. 5, no. 3. 